\title{
Deregulation of the phosphatase, PP2A is a common event in breast cancer, predicting sensitivity to FTY720
}

\author{
Shawn Baldacchino ${ }^{1 \dagger}$, Christian Saliba ${ }^{1 \dagger}$, Vanessa Petroni ${ }^{2}$, Anthony G Fenech ${ }^{2}$, Nigel Borg ${ }^{1}$ and Godfrey Grech ${ }^{1 *}$
}

\begin{abstract}
Background: The most commonly used biomarkers to predict the response of breast cancer patients to therapy are the oestrogen receptor (ER), progesterone receptor (PgR), and human epidermal growth factor receptor 2 (HER2). Patients positive for these biomarkers are eligible for specific therapies such as endocrine treatment in the event of ER and PgR positivity, and the monoclonal antibody, trastuzumab, in the case of HER2-positive patients. Patients who are negative for these three biomarkers, the so-called triple negatives, however, derive little benefit from such therapies and are associated with a worse prognosis. Deregulation of the protein serine/threonine phosphatase type 2A (PP2A) and its regulatory subunits is a common event in breast cancer, providing a possible target for therapy.
\end{abstract}

Methods: The data portal, cBioPortal for Cancer Genomics was used to investigate the incidence of conditions that are associated with low phosphatase activity. Four (4) adherent human breast cancer cell lines, MDA-MB-468, MDA-MB-436, Hs578T and BT-20 were cultured to assess their viability when exposed to various dosages of rapamycin or FTY720. In addition, RNA was extracted and CDNA was synthesised to amplify the coding sequence of PPP2CA. Amplification was followed by high-resolution melting to identify variations.

Results and conclusion: The sequence of PPP2CA was found to be conserved across a diverse panel of solid tumour and haematological cell lines, suggesting that low expression of PPP2CA and differential binding of inhibitory PPP2CA regulators are the main mechanisms of PP2A deregulation. Interestingly, the cBioPortal for Cancer Genomics shows that PP2A is deregulated in $59.6 \%$ of basal breast tumours. Viability assays performed to determine the sensitivity of a panel of breast cancer cell lines to FTY720, a PP2A activator, indicated that cell lines associated with ER loss are sensitive to lower doses of FTY720. The subset of patients with suppressed PP2A activity is potentially eligible for treatment using therapies which target the PI3K/AKT/mTOR pathway, such as phosphatase activators.

Keywords: Predictive biomarkers, PP2A, Therapeutic groups, Personalised medicine

\section{Overview}

Breast cancer accounts for approximately $23 \%$ of cancer cases in females and is responsible for $14 \%$ of cancerrelated deaths in females [1]. The classification of breast cancer is shifting to an expression-oriented classification. Histological assessment is still a vital tool for assessing prognosis through stage (lymph node status, tumour size

\footnotetext{
* Correspondence: godfrey.grech@um.edu.mt

${ }^{\dagger}$ Equal contributors

'Department of Pathology, Medical School, University of Malta, Msida MSD2090, Malta

Full list of author information is available at the end of the article
}

and grade). Immunohistological investigations are instrumental in defining subtypes and for planning treatment strategies. Breast cancer is being classified into four broad categories: luminal A, luminal B, the human epidermal growth factor receptor 2 (HER2)-enriched and basal-like. The luminal class indicates oestrogen receptor (ER) and/or progesterone receptor (PgR) positivity but a negative HER2 and a low Ki-67 expression $(<14 \%)$ for the A subtype. Luminal B is subdivided into the HER2 negative along with high Ki-67 and the HER2 positive. The HER2-enriched are negative 
for both the ER and PgR while the basal-like class is in its majority negative for all threehormone receptors (triple negative). ER and PgR receptor expression confers susceptibility to endocrine therapy whereas HER2-positive breast cancer is treated with trastuzumab (anti-HER2 treatment) [2,3].

Treatment of the basal-like class is currently based on cytotoxic drugs and have a worse overall and diseasefree survival $[2,4]$. A small subclass, referred to as the special histological types (being medullary and adenoid cystic carcinomas) can still be eligible to endocrine treatment [2]. Interestingly, the basal subtype shows a higher occurrence of phosphatidylinositol 3-kinase (PI3K) pathway activation [5].

Receptor tyrosine kinases such as HER2 and insulinlike growth factor 1 (IGF-1) receptor activate the PI3K pathway, initiating a cascade of signals. Active PI3K generates phosphatidylinositol 3,4,5 triphosphate (PIP3), which serves as an anchor for Pleckstrin homology (PH) domain-containing proteins, including both adaptor molecules such as GRB2-associated binding protein 2 (Gab2) and docking protein 1 (Dok1) and kinases such as tec protein tyrosine kinase (Tec), Bruton agammaglobulinemia tyrosine kinase (Btk), phosphoinositidedependent kinase-1 (PDK1) and v-akt murine thymoma viral oncogene homolog kinase (AKT) [6-9]. Activation of AKT increases cell cycle progression and maintains mammalian target of rapamycin (mTOR) signalling resulting in enhanced cell proliferation and survival, respectively. The PI3K pathway is attenuated by phosphatases, including phosphatase and tensin homolog (PTEN) which dephosphorylates PIP3 [10] and protein serine/threonine phosphatase type 2A (PP2A) which inactivates mTOR effectors [11].

PP2A is a complex of multiple subunits that interact to define the enzyme's substrate targets. Moreover, other regulatory subunits may bind to the complex to regulate its activity. Hence, understanding the structure of PP2A and its interactions with associated proteins sheds light on its regulation and its substrates. PP2A controls the phosphorylation of a number of kinases involved in cell signalling by catalysing dephosphorylation of the downstream intracellular proteins. As PP2A activity regulates various pathways, its downregulation may be involved in the progression of multiple tumour types $[12,13]$. The role of PP2A has been studied extensively in various cellular models, and deregulation of PP2A and its subunits (alpha4 and SET) are implicated in enhanced proliferation and differentiation block in haematopoietic progenitor cultures [14]. Missense mutations in the structural subunits, PPP2R1A and PPP2R1B, result in suppressed PP2A complex formation. Loss of heterozygosity is observed in a significant percentage of breast, lung, ovarian, colon and liver and melanoma malignancies and to a lesser extent in
non-Hodgkin's lymphomas and chronic lymphocytic leukaemia [15-20]. Somatic missense mutations were also detected in PPP2R1A in high-grade serous endometrial tumours [21]. A particular study has shown that PPP2R1B is mutated in $13 \%$ of breast cancers, and these mutations result in defective attachment of the $B$ and $C$ subunits. Whole gene deletions, missense, frame-shift, internal and C-terminal protein deletions are likely to hinder the formation of the PP2A active core dimer. Half of the breast cancers investigated had a low expression of PPP2R1B, contributing to malignant transformation [17,22]. In fact, PPP2R1B has been described as a tumour suppressor gene as it is often found to be deleted in human breast cancer. In addition, inactivation of PP2A by phosphorylation at tyrosine 307 is significantly correlated with HER2-positive tumour progression [23].

Loss of function of the phosphatases PTEN [24] and inositol polyphosphate 4-phosphatase type II (INPP4B) [25] is associated with aggressive basal-like breast carcinoma. PTEN, INPP4B and PP2A are known antagonists of AKT phosphorylation; hence, loss of phosphatase function leads to increased AKT activation. Interestingly, BRCA1 is known to activate PP2A, a phosphatase that dephosphorylates AKT at threonine 308 (T308) and serine 473 (S473) $[26,27]$. This is supported by the findings that loss of BRCA1 activity leads to increased AKT activity [28] and reduced PP2A activity [26]. In addition, BRCA1 is known to bind phosphorylated AKT (p-AKT) and lead to its ubiquitination [29]. In fact, an enhanced stability and higher expression of p-AKT can be found in BRCA1 mutants, in which the mutant BRCA1 lacks the ability to bind to pAKT [28].

Overexpression of the PP2A biomarkers p-S6K and p$\mathrm{AKT}$ has been described in breast and ovarian tumours potentially reflecting attenuated PP2A activity [30-33]. New insights into the mechanism of PP2A regulation in solid tumours form the basis of potential identification of variants that affect the phosphatase activity. The regulating subunits CIP2A (cancerous inhibitor of PP2A, also known as KIAA1524) and SET bind to the PP2A complex and specify its targets. These subunits were found to be overexpressed in various tumours including breast, colon and renal tumours, respectively [34-36].

In this study, we scanned for mutations in the PP2A catalytic subunit, PPP2CA transcript (mRNA) in various breast cancer cell lines. Publically available datasets (cBioPortal) were used to investigate the frequency of mutations and expression of the PP2A complex components and regulatory subunits. Of interest, the cBioPortal for Cancer Genomics shows that the PP2A complex is deregulated in $59.6 \%$ of basal breast tumours. Investigations to determine the sensitivity of a panel of breast cancer cell lines to FTY720, a PP2A activator, indicated that cell lines associated with ER loss are sensitive to 
lower doses of FTY720. Interestingly, using the specific inhibitor of the mTOR kinase, rapamycin, on the same panel of breast cancer cell lines resulted in a different sensitivity profile. Our interest in the use of FTY720 originates from the observations in our preliminary studies showing enhanced sensitivity of a BRCA1 mutant breast cancer cell line to FTY720 (unpublished).

These cases are eligible to pharmaceutical inhibition of the PI3K pathway and potentially activation of the phosphatase PP2A. Activation of PP2A will allow not only targeting of the deregulated PI3K pathway, including kinase mutants and cells with a low PTEN expression, but also BRCA1 mutants due to the sensitivity conferred by the lower PP2A activity.

\section{Methods}

Data mining using cBioPortal for Cancer Genomics

A data portal (cBioPortal for Cancer Genomics [37]), available at http://www.cbioportal.org was used to measure the incidence of conditions that are associated with low phosphatase activity, as per the criteria in Table 1 [37]. The database query was based on deregulation (mutant and altered expression) of the PP2A complex components and upregulation (expression) of the inhibitory regulators of the complex.

\section{Cell lines used and culturing conditions}

Four (4) adherent human breast cancer cell lines were used in the study, namely MDA-MB-468, MDA-MB-436, Hs578T and BT-20. The cells were cultured in sterile T-25 flasks in an incubator at $37^{\circ} \mathrm{C}$, having an atmosphere of 5\% $\mathrm{CO}_{2}$ and 98\% humidity, using RPMI 1640 medium containing $10 \%$ foetal bovine serum (FBS) and 1\% penicillin/streptomycin. Passaging was carried out when the cells reached around $90 \%$ confluence.

\section{RNA extraction and cDNA synthesis}

Cell pellets were prepared from 3 to $5 \times 10^{6}$ cells. Cells were lysed in QIAzol and stored at $-80^{\circ} \mathrm{C}$. RNA was extracted using RNeasy isolation kit (Qiagen, Venlo, The
Netherlands). Quality was validated by spectrophotometry $260 / 280$ and 260/230 ratios using the nanodrop, and the integrity was checked using the Agilent Bioanalyser, Santa Clara, CA, USA.

RNA was reverse transcribed into cDNA using the Quantitect Reverse Transcription Kit from Qiagen. This kit provides high cDNA yields even from low abundance transcripts and eliminates genomic DNA contamination effectively.

\section{High-resolution melting}

Primers were designed to amplify the coding sequence of PPP2CA into individual 250 to $300 \mathrm{bp}$ overlapping fragments by polymerase chain reaction (PCR). Amplification was followed by HRM, using a Qiagen RotorGene instrument. Variants were characterised by their melting temperatures through the distinct kinetics of fluorescence loss during HRM. Shifts in the melting temperature or HRM peaks were identified visually using the Rotor-Gene software and also using the Rotor-Gene ScreenClust HRM Software. The latter software processes data generated throughout the amplification and HRM in order to segregate samples into potentially distinct groups. To characterise the variations, the whole PPP2CA coding sequence was amplified using the terminal primers in a conventional PCR. Products were purified using the Wizard ${ }^{\circ}$ SV Gel and PCR CleanUp System (Promega, Madison, WI, USA). The full-length PPP2CA amplicons were sequenced to confirm the HRM results.

\section{Cell line sensitivity assays}

The adherent human breast cancer cell lines described above were plated in 24 well plates to determine two seeding densities to be used for the sensitivity assays that run for $48 \mathrm{~h}$. Selection of the cell densities was based on (1) reaching a confluence of $80 \%$ at the time point of drug administration and in different wells (2) reaching a confluence of $80 \%$ following $72 \mathrm{~h}$ of seeding. Cells were plate in triplicates and incubated for $24 \mathrm{~h}$ to allow

Table 1 Criteria used to select breast cancer cases with deregulated PP2A in the cBioPortal for Cancer Genomics

\begin{tabular}{lc}
\hline Variable & \multicolumn{1}{c}{ Criteria } \\
\hline Selects low expression (including deletions) of one of the pp2a complex components & Homozygous deletions; downregulation (fold change $<-2$ ) \\
PPP2CA & \\
PPP2CB & Amplification; upregulation (fold change >2) \\
PPP2R2A & \\
Selects high expression, including amplification, of the inhibitory regulatory subunits & \\
KIAA1524 (cip2a) & \\
SETBP1 & \\
SET & \\
IGBP1 (alpha4) & \\
\hline
\end{tabular}


adherence. At $24 \mathrm{~h}, \mathrm{FTY720}$ was added at a final concentration ranging from 0.5 to $25 \mu \mathrm{M}$, while rapamycin was added in a separate experiment at a final concentration ranging from 10 to $100 \mu \mathrm{M}$. A vehicle control and an untreated control were added. An MTT (3-(4,5-dimethylthiazol-2-yl)-2,5-diphenyltetrazolium bromide) assay was performed at the end of the incubation periods (24 and $48 \mathrm{~h}$ ) to determine cell viability. A replicate experiment to confirm the results was done.

\section{Results}

In this study, no mutations were identified in the PPP2CA coding sequence in various breast cancer cell lines. In silico analysis using a publically available dataset, the cBioPortal for Cancer Genomics, shows that the protein phosphatase 2 ( $\mathrm{PP} 2 \mathrm{~A})$ complex is deregulated in $59.6 \%$ of basal breast tumours. In a panel of breast cancer cell lines, ER loss correlates with sensitivity to lower doses of FTY720.

\section{PPP2CA coding sequence is highly conserved}

Screening of PPP2CA coding sequence for mutations, using HRM analysis, could not detect mutations in the adherent human breast cancer cell lines and in an additional panel of 25 tumour cell lines (14 haematological and 11 solid tumour cell lines). The wild-type sequence was confirmed in the human breast cancer cell lines used in this study (data not shown) by re-sequencing.

\section{Protein phosphatase type 2A (PP2A) is deregulated in $59.6 \%$ of basal breast tumours}

Analysing the results from datasets originating from RNAseq in the cBioPortal, and using the criteria described above, $46.7 \%$ (245 cases out of 525 eligible cases) of all the subtypes of breast cancer patients either had a low expression, including deletions, of one of the PP2A complex components or a high expression, including amplification, of the inhibitory regulatory subunits
(Figure 1). Interestingly, the criteria were generally mutually exclusive, except for PPP2CB and the PPP2R2A which can occur simultaneously.

Surprisingly, $8.6 \%$ of the patients either had a high expression of CIP2A (KIAA1524) or a high expression of SET, implying that the PP2A complex is sequestered from the negative feedback on mTOR signalling. Although overall, the PPP2CA expression is low in $4.2 \%$ of the patients, the low expression was associated mainly with the basal phenotype. In addition, PP2A deregulation is associated with $59.6 \%$ of the basal phenotype (Table 2).

\section{Cell lines associated with ER loss are sensitive to lower doses of FTY720}

The cell lines, BT20 and Hs578T, were found to be sensitive to 0.05 and $0.1 \mu \mathrm{M}$ FTY720, respectively. A significant reduction in the metabolism of these cells persisted up to $5 \mu \mathrm{M}$, with a percentage viability of $60 \%$ in BT20 and $80 \%$ in Hs578T, when compared to the vehicle control culture (Figure 2A). Of interest, both these cell lines have no ER expression or express a truncated, inactive ER. In contrast, the BT20 cell line is resistant to rapamycin, while Hs578T was extremely sensitive to low doses with an $\mathrm{IC}_{50}$ reached at $10 \mu \mathrm{M}$ (Figure $2 \mathrm{~B}$ ). The other breast cancer cell lines studied proliferated in the presence of $5 \mu \mathrm{M}$ FTY720 and reached an $\mathrm{IC}_{50}$ at approximately $35 \mu \mathrm{M}$ of rapamycin.

\section{Results interpretation}

In this study, we observed that the PPP2CA coding sequence is not polymorphic in various tumour cell lines tested. The PPP2CA gene sequence is highly conserved throughout species (ENSEMBLE version release $72[38]$ ). Currently, 25 missense variants, 4 stop codon gains and 2 frame-shift variants have been described in literature. Although the mutational analysis did not yield any missense mutations, in silico analysis of publically available

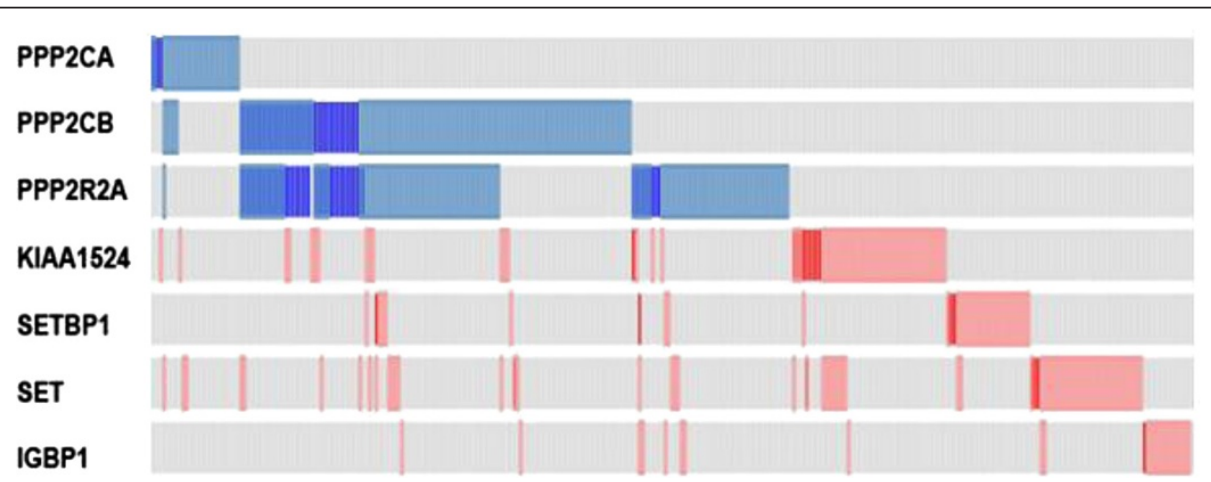

Figure 1 Distribution of aberrations associated with low PP2A activity. In this analysis, all subtypes of breast cancer patients were included. Blue bars indicate low expression (light) or homozygous deletion (dark), while the red bars indicate high expression (light) or amplification (dark) (KIAA1524 is equivalent to CIP2A; IGBP1 is equivalent to alpha4). 
Table 2 Incidence distribution of aberrations associated with low PP2A activity in the various breast cancer subtypes

\begin{tabular}{|c|c|c|c|c|c|}
\hline & Basal $(N=99)$ & Luminal A $(N=235)$ & Luminal B $(N=133)$ & HER2-enriched $(N=58)$ & Total $(N=525)$ \\
\hline PPP2CA & $17.2 \%$ & $0.4 \%$ & $2.3 \%$ & $1.7 \%$ & $4.2 \%$ \\
\hline PPP2CB & $21.2 \%$ & $14.9 \%$ & $30.8 \%$ & $25.9 \%$ & $21.3 \%$ \\
\hline PPP2R2A & $18.2 \%$ & $11.9 \%$ & $24.1 \%$ & $24.1 \%$ & $17.5 \%$ \\
\hline CIP2A & $18.2 \%$ & $3.0 \%$ & $10.5 \%$ & $10.3 \%$ & $8.6 \%$ \\
\hline SETBP1 & $4.0 \%$ & $6.4 \%$ & $7.5 \%$ & $0.0 \%$ & $5.5 \%$ \\
\hline SET & $15.2 \%$ & $2.6 \%$ & $8.3 \%$ & $24.1 \%$ & $8.8 \%$ \\
\hline IGBP1 & $4.0 \%$ & $7.7 \%$ & $2.3 \%$ & $3.4 \%$ & $5.0 \%$ \\
\hline Total PP2A deregulation & $59.6 \%$ & $35.3 \%$ & $51.9 \%$ & $58.6 \%$ & $46.7 \%$ \\
\hline
\end{tabular}

RNAseq datasets (cBioPortal) indicated clearly that deregulation of the PP2A complex mainly occurs through altered expression of the subunits and inhibitory regulators. Indeed, $17.2 \%$ of cases with the basal subtype showed low expression or homozygous deletion of the catalytic subunit, PPP2CA; 18.2\% were associated with high expression of CIP2A and 15.2\% with high expression of SET (Table 2). Overall, PP2A is deregulated in $59.6 \%$ of basal breast tumours.

Cytoplasmic CIP2A overexpression at mRNA and protein levels correlates with high tumour grade and aggressiveness in breast cancer patients [34,39]. Overexpression of CIP2A in normal tissues is only restricted to brain, prostate and testis, but it is undetectable in normal breast tissue. Overexpression is a common occurrence in malignancy including colon, prostate, ovarian cancer and head and neck squamous cell carcinomas and is most often related to the more aggressive cases of high-grade or advanced tumour stages [35,40-43]. CIP2A overexpression clustered mainly with basal-like breast tumours. Out of 40 breast cancer cell lines, basal-like breast tumour cell lines exhibited the highest CIP2A overexpression [44]. Similarly, SET and alpha4 (IGBP1) are implicated in promoting the progression of disease and enhanced proliferative signals in leukaemogenesis $[14,45]$. Of interest, expression of the alpha4 inhibitory subunit is dependent on the efficiency of translation initiation, promoted by the mTOR pathway. Hence, expression should be measured at a protein level, and the incidence of high alpha4 expression is expected to be greater than $3 \%$ (Figure 1, IGBP1). Although no data on the protein expression of alpha4 is available in the cBioPortal, the Human Protein Atlas hints to an increased expression of alpha4 protein in breast tumour as opposed to normal breast tissue through immunohistochemical analysis.

Binding of alpha4 to the PP2A complex shifts the phosphatase activity from a negative feedback mechanism that attenuates proliferation (mTOR signalling) to a pro-survival activity (Figure 3 ) through inactivation of p53 [46-48]. To support the importance of substrate specificity following regulatory subunit binding to the PP2A complex, studies indicate that the SET-PP2A complex activates the ERK/MAPK pathway inhibiting apoptosis [49] and the CIP2A-PP2A complex releases inhibition on $\mathrm{p}-\mathrm{AKT}$ and $\mathrm{c}-\mathrm{Myc}$ and hence promotes proproliferative signals [50]. This implies that the PP2A complex shifts from a tumour suppressor to a promoter of oncogenic signals.

Deregulation of p53 is a frequent event in breast cancer associated with $33 \%$ of breast cancer patients [37]. Formation of the PP2A-alpha4 complex is an alternative mechanism promoting cell survival through p53 inactivation (Figure 3).

Another hallmark of the molecular basis of breast cancer is the loss of function of BRCA1. BRCA1 mutations occur in approximately 50\% of hereditary breast cancers, but a low expression of this gene was observed in $40 \%$ to $80 \%$ of cases [51]. Interestingly, BRCA1 has been shown to activate PP2A [26], and a low BRCA1 expression correlate with elevated phosphorylation of AKT [51]. In addition, IGF-1-induced activation of $\mathrm{p}-\mathrm{AKT}$ is inhibited by FTY720 in the BRCA1 mutant cell line, HCC1937 (data not shown), indicating that loss of function of BRCA1 leads to low phosphatase activity and higher sensitivity to PP2A activators.

In this study, viability assays showed that cell lines associated with oestrogen receptor (ER) loss are sensitive to lower doses of FTY720. ER-negative breast cancer cell lines have a suppressed PP2A activity, when compared to breast cancer cell lines expressing ER receptors [52], supporting the higher sensitivity to the phosphatase activator, FTY720. ER-dependent BRCA1 expression [53] provides a plausible mechanism (Figure 3), since low expression of BRCA1 in ER-negative cell lines results in a reduced ability to activate $\mathrm{PP} 2 \mathrm{~A}$. Of interest, viability of the ER-negative cell line, BT-20, was unaffected by rapamycin up to a high dose $(35 \mu \mathrm{M})$. Hence, the sensitivity to PP2A activation in the BT-20 cell line is not dependent on the attenuation of the mTOR kinase, which is specifically inhibited by rapamycin. This suggests that the formation of the core PP2A complex, following pharmacological activation by FTY720, 


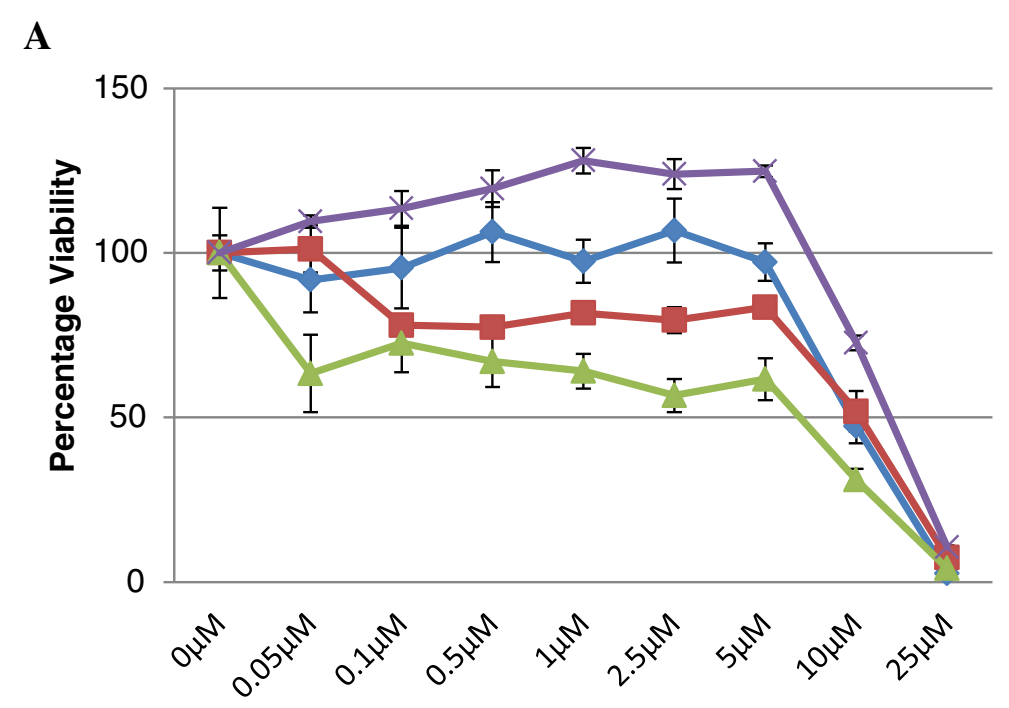

FTY720 Concentration

B

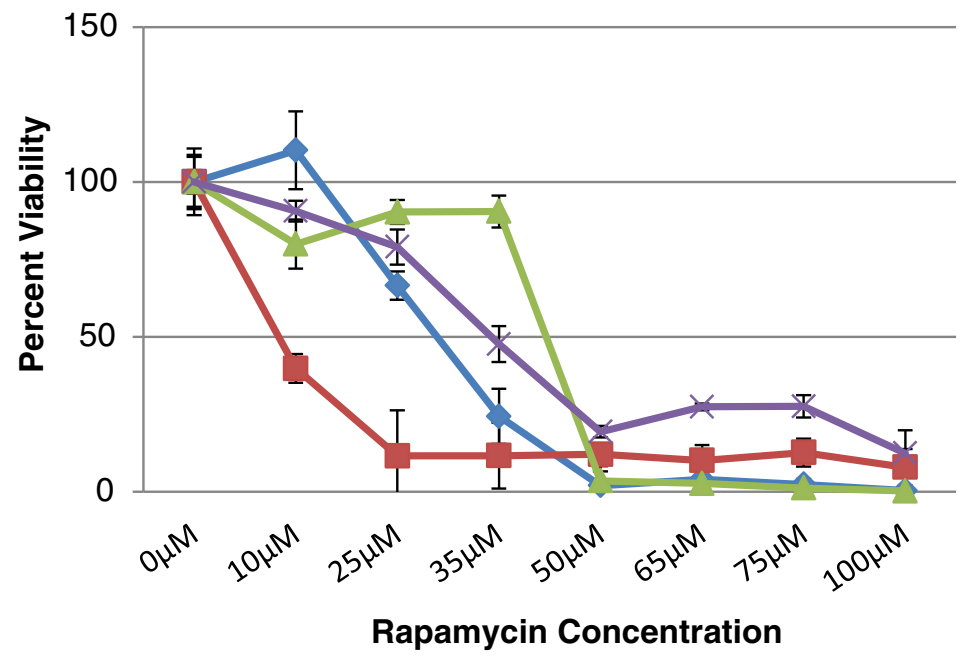

$\sim$ MDAMB468 $\leftarrow$-HS578T $\leftarrow$ BT20 $*$ MDAMB436

Figure 2 Viability assays of breast cancer cell lines. Cells were cultured in the presence or absence of FTY720 (A) or rapamycin (B) using a concentration gradient and absorbance was measured after $48 \mathrm{~h}$ of drug exposure. Each data point is an average of three independent experiments, with triple measurements for each experiment. The viability of each well is expressed as a percentage normalised to vehicle control cells. The standard error is indicated using error bars. The blue lines plot the percent viability of MDAMB468, the red line Hs578T, the green line BT20 and the purple line of MDAMB436.

dephosphorylates the mTOR downstream effectors, 4EBP and S6K, and concurrently releases the block on the p53 pathway. Our results suggest that markers can be used to predict sensitivity to FTY720 and that the pharmacological activation of PP2A is an attractive therapeutic modality that simultaneously targets proliferative signals and releases PP2A-dependent p53 inhibition. In addition, the use of FTY720 is a potential alternative therapy to inhibitors of the kinase mTOR, which proved to have limited success due to resistance to therapy. A panel of biomarkers that predict sensitivity to mTOR inhibitors [54] and activation of the phosphatase, PP2A, merit further investigation to allow characterisation of the potential therapeutic group. This approach utilise the use of efficacy biomarkers, assessing the beneficial effects of a clinically available treatment, promoting personalised medicine [55]. 


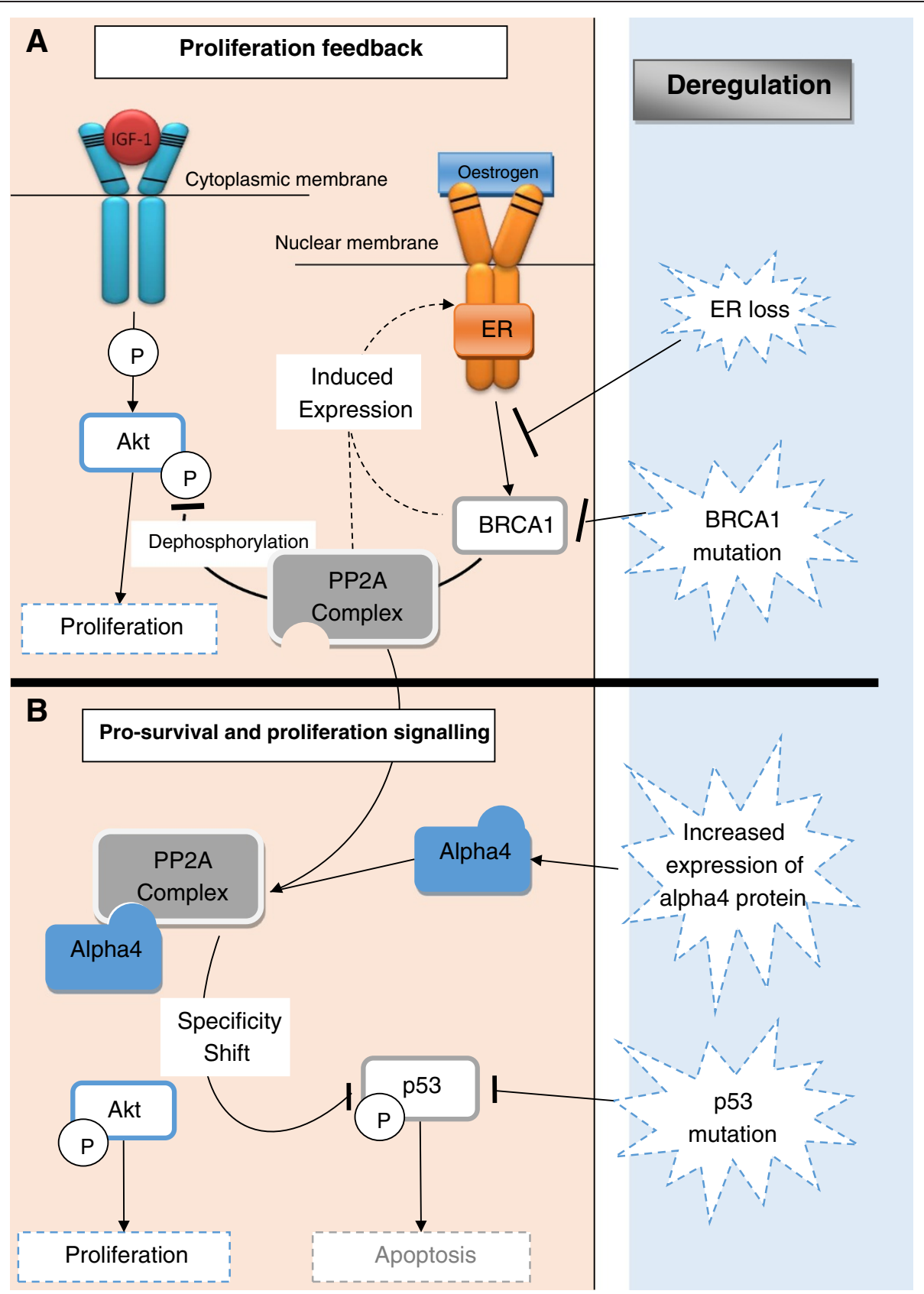

Figure 3 Schematic diagram illustrating the dual role of PP2A complex. PP2A complex attenuates the proliferative signals transduced via the AKT/mTOR pathway. Activation of PP2A is dependent on ER-induced BRCA1 expression. Attenuation mechanism following

(A) haploinsufficiency or loss of function of ER or BRCA1 or (B) increased expression of the inhibitory regulatory subunit, alpha4. Alpha4 sequestrated the PP2A complex, maintaining AKT/mTOR signals and shifts the specificity of the PP2A-alpha4 complex towards pro-survival signals, via dephosphorylation of p53.

\section{Expert recommendations}

The characterisation of the molecular mechanism of disease allows classification of patients into subtypes and potentially identifies specific targets for therapeutic intervention. Tyrosine kinase mutations are central to specific targeted therapy. Investigation of kinase deregulation within particular patient groups has led to identification of mutant tyrosine kinases associated with disease progression and therapy modulation. Biomarkerspecific therapies emerged, taking a leading role in guidedtherapy. Loss of function mutations in the phosphatase, PP2A, and/or an enhanced PP2A inhibition due to increased expression of PP2A regulators (such as CIP2A, SETBP1) will provide a new classification of 
patients in various malignancies. Of interest, these subtypes will provide the basis to investigate the use of PP2A activators as therapeutic drugs, hence promoting personalised medicine. Current diagnostic panels assessing risk, early diagnosis and patient management require a more robust platform, integrating classifier biomarkers, clinical data and creation of individual patient profiles [56]. In this study, we promote the use of biomarkers to assess the potential use of specific drugs in stratified therapeutic groups.

\section{Competing interests}

The authors declare that they have no competing interests.

\section{Authors' contributions}

SB carried out the cell culturing experiments and data analysis and contributed to the draft of the manuscript. CS carried out the HRM analysis, VP worked on the sensitivity of cell lines using rapamycin, AF participated in experimental design and critical review of the manuscript, NB did the work on the sensitivity of the BRCA1 mutant cell line and GG conceived the study, designed and coordinated the project and contributed to the writing of the manuscript. All authors read and approved the final manuscript.

\section{Acknowledgments}

We would like to thank Professor Andrew Hanby, Professor Valerie Speirs and Dr Thomas A Hughes for the breast cancer cell lines used in this study. This research was supported by the Faculty of Medicine and Surgery, University of Malta.

\section{Author details}

${ }^{1}$ Department of Pathology, Medical School, University of Malta, Msida MSD2090, Malta. ${ }^{2}$ Department of Clinical Pharmacology and Therapeutics, University of Malta, Msida MSD2090, Malta.

Received: 13 December 2013 Accepted: 9 January 2014 Published: 25 January 2014

\section{References}

1. Jemal A, Bray F, Center MM, Ferlay J, Ward E, Forman D: Global cancer statistics. CA Cancer J Clin 2011, 61(2):69-90.

2. Goldhirsch A, Wood WC, Coates AS, Gelber RD, Thurlimann B, Senn HJ: Strategies for subtypes-dealing with the diversity of breast cancer: highlights of the St Gallen international expert consensus on the primary therapy of early breast cancer 2011. Ann Oncol 2011, 22(8):1736-1747.

3. Schnitt SJ: Classification and prognosis of invasive breast cancer: from morphology to molecular taxonomy. Mod Pathol 2010, 23:S60-S64.

4. Onitilo AA, Engel JM, Greenlee RT, Mukesh BN: Breast cancer subtypes based on ER/PR and Her2 expression: comparison of clinicopathologic features and survival. Clin Med Res 2009, 7(1-2):4-13.

5. Umemura S, Yoshida S, Ohta Y, Naito K, Osamura RY, Tokuda Y: Increased phosphorylation of Akt in triple-negative breast cancers. Cancer Sci 2007, 98(12):1889-1892.

6. Leevers SJ, Vanhaesebroeck B, Waterfield MD: Signalling through phosphoinositide 3-kinases: the lipids take centre stage. Curr Opin Cell Biol 1999, 11(2):219-225.

7. Saito K, Scharenberg AM, Kinet JP: Interaction between the Btk PH domain and phosphatidylinositol-3,4,5-trisphosphate directly regulates Btk. J Biol Chem 2001, 276(19):16201-16206.

8. Stokoe D, Stephens LR, Copeland T, Gaffney PR, Reese CB, Painter GF, Holmes AB, McCormick F, Hawkins PT: Dual role of phosphatidylinositol3,4,5-trisphosphate in the activation of protein kinase B. Science 1997 277(5325):567-570.

9. Tang B, Mano H, Yi T, Ihle JN: Tec kinase associates with c-kit and is tyrosine phosphorylated and activated following stem cell factor binding. Mol Cell Biol 1994, 14(12):8432-8437.

10. Russillo M, Di Benedetto A, Metro G, Ferretti G, Papaldo P, Cognetti F, Mottolese M, Fabi A: Assessment of PTEN and PI3K status in primary breast cancer and corresponding metastases: is it worthwhile? J Clin Oncol 2011, 29(20):2834-2835. author reply 2835.
11. Liu L, Chen L, Luo Y, Chen W, Zhou H, Xu B, Han X, Shen T, Huang S: Rapamycin inhibits IGF-1 stimulated cell motility through PP2A pathway. PLoS One 2010, 5(5):e10578.

12. Peyssonnaux C, Eychene A: The Raf/MEK/ERK pathway: new concepts of activation. Biol Cell 2001, 93(1-2):53-62.

13. Silverstein AM: Actions of PP2A on the MAP kinase pathway and apoptosis are mediated by distinct regulatory subunits. Proc Natl Acad Sci 2002, 99(7):4221-4226.

14. Grech G, Blazquez-Domingo M, Kolbus A, Bakker WJ, Mullner EW, Beug H, von Lindern M: Igbp1 is part of a positive feedback loop in stem cell factor-dependent, selective mRNA translation initiation inhibiting erythroid differentiation. Blood 2008, 112(7):2750-2760.

15. Calin GA, lasio MG, Caprini E, Vorechovsky I, Natali PG, Sozzi G, Croce CM, Barbanti-Brodano G, Russo G, Negrini M: Low frequency of alterations of the $a(P P P 2 R 1 A)$ and $\beta$ (PPP2R1B) isoforms of the subunit $A$ of the serine-threonine phosphatase $2 \mathrm{~A}$ in human neoplasms. Oncogene 2000, 19:1191-1195.

16. Ruediger R, Ruiz J, Walter G: Human cancer-associated mutations in the Aa subunit of protein phosphatase $2 \mathrm{~A}$ increase lung cancer incidence in Aa knock-in and knockout mice. Mol Cell Biol 2011, 31(18):3832-3844.

17. Janssens V, Goris J, Van Hoof C: PP2A: the expected tumor suppressor. Curr Opin Genet Dev 2005, 15(1):34-41.

18. Wang SS, Esplin ED, Li JL, Huang L, Evans GA: Alterations of the PPP2R1B gene in human lung and colon cancer. Science 1998, 282(5387):284-287.

19. Takagi Y, Futamura M, Yamaguchi K, Aoki S, Takahashi T, Saji S: Alterations of the PPP2R1B gene located at 11q23 in human colorectal cancers. Gut 2000, 47(2):268-271.

20. Chou H-C, Chen C-H, Lee H-S, Lee C-Z, Huang G-T, Yang P-M, Lee PH, Sheu $J C$ : Alterations of tumour suppressor gene PPP2R1B in hepatocellular carcinoma. Cancer Lett 2007, 253(1):138-143.

21. Stebbing J, Lit LC, Zhang H, Darrington RS, Melaiu O, Rudraraju B, Giamas G: The regulatory roles of phosphatases in cancer. Oncogene 2013. doi:10.1038/onc.2013.80.

22. Sablina AA, Chen W, Arroyo JD, Corral L, Hector M, Bulmer SE, DeCaprio JA, Hahn WC: The tumor suppressor PP2A A $\beta$ regulates the RalAGTPase. Cell 2007, 129(5):969-982.

23. Wong LL, Zhang D, Chang CF, Koay ES: Silencing of the PP2A catalytic subunit causes HER-2/neu positive breast cancer cells to undergo apoptosis. Exp Cell Res 2010, 316(20):3387-3396.

24. Marty B, Maire V, Gravier E, Rigaill G, Vincent-Salomon A, Kappler M, Lebigot I, Djelti F, Tourdès A, Gestraud P, Hupé P, Barillot E, Cruzalegui F, Tucker GC, Stern MH, Thiery JP, Hickman JA, Dubois T: Frequent PTEN genomic alterations and activated phosphatidylinositol 3-kinase pathway in basal-like breast cancer cells. Breast Cancer Res 2008, 10(6): R101.

25. Gewinner C, Wang ZC, Richardson A, Teruya-Feldstein J, Etemadmoghadam D, Bowtell D, Barretina J, Lin WM, Rameh L, Salmena L, Pandolfi PP, Cantley LC: Evidence that inositol polyphosphate 4-phosphatase type II is a tumor suppressor that inhibits PI3K signaling. Cancer cell 2009, 16(2):115-125

26. Ma Y, Hu C, Riegel AT, Fan S, Rosen EM: Growth factor signaling pathways modulate BRCA1 repression of estrogen receptor-alpha activity. Mol Endocrinol 2007, 21(8):1905-1923.

27. Ugi S, Imamura T, Maegawa H, Egawa K, Yoshizaki T, Shi K, Obata T, Ebina Y, Kashiwagi A, Olefsky JM: Protein phosphatase 2A negatively regulates insulin's metabolic signaling pathway by inhibiting Akt (protein kinase B) activity in 3 T3-L1 adipocytes. Mol Cell Biol 2004, 24(19):8778-8789.

28. Xiang T, Ohashi A, Huang Y, Pandita TK, Ludwig T, Powell SN, Yang Q: Negative regulation of AKT activation by BRCA1. Cancer Res 2008, 68(24):10040-10044.

29. Chen J, Silver DP, Walpita D, Cantor SB, Gazdar AF, Tomlinson G, Couch FJ, Weber BL, Ashley T, Livingston DM, Scully R: Stable interaction between the products of the BRCA1 and BRCA2 tumor suppressor genes in mitotic and meiotic cells. Mol Cell 1998, 2(3):317-328.

30. Filonenko V, Tytarenko R, Azatjan S, Savinska L, Gaydar Y, Gout I, Usenko VS, Lyzogubov W: Immunohistochemical analysis of S6K1 and S6K2 localization in human breast tumors. Exp Oncol 2004, 26(4):294-299.

31. Zhou X: Activation of the Akt/mammalian target of rapamycin/4E-BP1 pathway by ErbB2 overexpression predicts tumor progression in breast cancers. Clin Cancer Res 2004, 10(20):6779-6788. 
32. Stål O, Pérez-Tenorio G, Åkerberg L, Olsson B, Nordenskjöld B, Skoog L, Rutqvist LE: Akt kinases in breast cancer and the results of adjuvant therapy. Breast Cancer Res 2003, 5(2):R37-R44.

33. Cancer Genome Atlas Network: Comprehensive molecular portraits of human breast tumours. Nature 2012, 490(7418):61-70.

34. Come C, Laine A, Chanrion M, Edgren H, Mattila E, Liu X, Jonkers J, Ivaska J, Isola J, Darbon JM, Kallioniemi O, Thézenas S, Westermarck J: CIP2A Is associated with human breast cancer aggressivity. Clin Cancer Res 2009, 15(16):5092-5100.

35. Junttila MR, Puustinen P, Niemelä M, Ahola R, Arnold H, Böttzauw T, Ala-aho R, Nielsen C, Ivaska J, Taya Y, Lu SL, Lin S, Chan EK, Wang XJ, Grènman R, Kast J, Kallunki T, Sears R, Kähäri VM, Westermarck J: CIP2A Inhibits PP2A in human malignancies. Cell 2007, 130(1):51-62.

36. Carlson SG, Eng E, Kim EG, Perlman EJ, Copeland TD, Ballermann BJ: Expression of SET, an inhibitor of protein phosphatase $2 \mathrm{~A}$, in renal development and Wilms' tumor. J Am Soc Nephrol 1998, 9:1873-1880.

37. Cerami E, Gao J, Dogrusoz U, Gross BE, Sumer SO, Aksoy BA, Jacobsen A, Byrne CJ, Heuer ML, Larsson E, Antipin Y, Reva B, Goldberg AP, Sander C, Schultz N: The cBio cancer genomics portal: an open platform for exploring multidimensional cancer genomics data. Cancer Discovery 2012, 2(5):401-404.

38. Flicek P, Ahmed I, Amode MR, Barrell D, Beal K, Brent S, Carvalho-Silva D, Clapham P, Coates G, Fairley S, Fitzgerald S, Gil L, García-Girón C, Gordon L, Hourlier T, Hunt S, Juettemann T, Kähäri AK, Keenan S, Komorowska M, Kulesha E, Longden I, Maurel T, McLaren WM, Muffato M, Nag R, Overduin B, Pignatelli M, Pritchard B, Pritchard E, et al: Ensembl 2013. Nucleic Acids Res 2013, 41(D1):D48-D55.

39. Wang J, Li W, Li L, Yu X, Jia J, Chen C: CIP2A is over-expressed in acute myeloid leukaemia and associated with $\mathrm{HL} 60$ cells proliferation and differentiation. Int J Lab Hematol 2011, 33(3):290-298.

40. Böckelman C, Lassus H, Hemmes A, Leminen A, Westermarck J, Haglund C, Bützow R, Ristimäki A: Prognostic role of CIP2A expression in serous ovarian cancer. Br J Cancer 2011, 105(7):989-995.

41. Teng HW, Yang SH, Lin JK, Chen WS, Lin TC, Jiang JK, Yen CC, Li AF, Chen PC, Lan YT, Lin CC, Hsu YN, Wang HW, Chen KF: CIP2A Is a predictor of poor prognosis in colon cancer. J Gastrointest Surg 2012, 16(5):1037-1047.

42. Vaarala MH, Väisänen MR, Ristimäki A: CIP2A expression is increased in prostate cancer. J Exp Clin Cancer Res 2010, 29(1):136.

43. Laine A: The Role of an Oncoprotein CIP2a in Breast Carcinoma. Turku: University of Turku; 2013

44. Niemelä M, Kauko O, Sihto H, Mpindi JP, Nicorici D, Pernilä P, Kallioniemi $\mathrm{OP}$, Joensuu $\mathrm{H}$, Hautaniemi S, Westermarck J: CIP2A signature reveals the MYC dependency of CIP2A-regulated phenotypes and its clinical association with breast cancer subtypes. Oncogene 2012, 31(39):4266-4278

45. Neviani P, Santhanam R, Trotta R, Notari M, Blaser BW, Liu S, Mao H, Chang JS, Galietta A, Uttam A, Roy DC, Valtieri M, Bruner-Klisovic R, Caligiuri MA, Bloomfield CD, Marcucci G, Perrotti D: The tumor suppressor PP2A is functionally inactivated in blast crisis CML through the inhibitory activity of the BCR/ABL-regulated SET protein. Cancer Cell 2005, 8(5):355-368.

46. Kong $M$, Ditsworth $D$, Lindsten $T$, Thompson CB: $a 4$ is an essential regulator of PP2A phosphatase activity. Mol Cell 2009, 36(1):51-60.

47. Sablina, Hector M, Colpaert N, Hahn WC: Identification of PP2A complexes and pathways involved in cell transformation, Volume 70. 24th edition. ; 2010:10474-10484

48. Feng $Z$, Levine AJ: The regulation of energy metabolism and the IGF-1/mTOR pathways by the p53 protein. Trends Cell Biol 2010, 20(7):427-434

49. Westermarck J, Hahn WC: Multiple pathways regulated by the tumor suppressor PP2A in transformation. Trends Mol Med 2008, 14(4):152-160.

50. Chen KF, Liu CY, Lin YC, Yu HC, Liu TH, Hou DR, Chen PJ, Cheng AL: CIP2A mediates effects of bortezomib on phospho-Akt and apoptosis in hepatocellular carcinoma cells. Oncogene 2010, 29(47):6257-6266.

51. Xiang, Jia, Sherris, Li, Wang, Lu D, Yang Q: Targeting the Akt/mTOR pathway in Brca1-deficient cancers. Oncogene 2011, 30(21):2443-2450.

52. Keen JC, Zhou QH, Park BH, Pettit C, Mack KM, Blair B, Brenner K, Davidson NE: Protein phosphatase $2 A$ regulates estrogen receptor (ER) expression through modulation of ER mRNA stability. J Biol Chem 2005, 280(33):29519-29524.
53. Gorski JJ, Kennedy RD, Hosey AM, Harkin DP: The complex relationship between BRCA1 and ER in hereditary breast cancer. Clin Cancer Res 2009, 15(5):1514-1518.

54. Satheesha S, Cookson VJ, Coleman LJ, Ingram N, Madhok B, Hanby AM, Suleman CA, Sabine VS, Macaskill EJ, Bartlett JM, Dixon JM, MCElwaine JN, Hughes TA: Response to mTOR inhibition: activity of elF4E predicts sensitivity in cell lines and acquired changes in elF4E regulation in breast cancer. Mol Cancer 2011, 10(1):19.

55. Golubnitschaja O, Costigliola V, EPMA: General report \& recommendations in predictive, preventive and personalised medicine 2012: white paper of the European association for predictive, preventive and personalised medicine. EPMA J 2012, 3(1):14.

56. Golubnitschaja O, Yeghiazaryan K, Costigliola V, Trog D, Braun M, Debald M, Kuhn W, Schild HH: Risk assessment, disease prevention and personalised treatments in breast cancer: is clinically qualified integrative approach in the horizon? EPMA J 2013, 4(1):6.

doi:10.1186/1878-5085-5-3

Cite this article as: Baldacchino et al:: Deregulation of the phosphatase PP2A is a common event in breast cancer, predicting sensitivity to FTY720. The EPMA Journal 2014 5:3.

\section{Submit your next manuscript to BioMed Central and take full advantage of:}

- Convenient online submission

- Thorough peer review

- No space constraints or color figure charges

- Immediate publication on acceptance

- Inclusion in PubMed, CAS, Scopus and Google Scholar

- Research which is freely available for redistribution 